\title{
Level of Service for Parking Facilities
}

\author{
Yulong $\mathrm{He}^{1}$, Xiaoduan $\mathrm{Sun}^{2}$, Lizhen $\mathrm{Du}^{1}$, Ruan Jinmei ${ }^{3}$ and Subasish Das ${ }^{2}$ \\ 1. Metropolitan Transportation College, Beijing University of Technology, Beijing 100124, China \\ 2. Civil Engineering Department, University of Louisianan, Los Angeles 70508, USA \\ 3. Traffic Planning Department, Beijing Municipal Institute of City Planning and Design, Beijing 100045, China
}

\begin{abstract}
As the number of motor vehicles increasing rapidly, urban parking has become an intolerable problem in major cities in China. Parking facility service evaluations play an important role in urban transportation planning and operation. This paper introduces an LOS (level of service) concept based on a comprehensive parking study in Beijing, China. The LOS methodology is developed by an integrated evaluation model that reflects the user's perception of the quality of service. The method combines four important service variables, namely the ratio of peak-hour demand to capacity, average parking space occupying rate, parking cost, and circulation time, into one single index to quantitatively evaluate a parking facility's performance. The case studies at the end of the paper demonstrate the applicability of the method.
\end{abstract}

Key words: Parking facilities, level of service, integrated evaluation.

\section{Introduction}

With the rapid development of motorization, parking has become an intolerable problem in many large cities in China, particularly in its capital city, Beijing. The parking problem has worsened as the number of registered vehicles broke the 5 million mark in 2012 . This happened much earlier than the prediction made several years ago. Based on the statistics from Beijing Bureau of Transportation, the city's overall parking capacity can only satisfy $41 \%$ of parking demand at six central districts of Beijing. Parking facilities are an integral piece of the urban transportation system. Efficient evaluation of a parking facility's performance is important to parking service planning, design and operation.

Parking problems have a noticeable impact on traffic congestion in Beijing. To better plan and operate parking facilities, a study was conducted by the Transportation Research Center at Beijing University of Technology. The project's objective is to investigate existing problems in parking facility design and

Corresponding author: Yulong He, Ph.D., associate professor, research fields: traffic safety and planning. E-mail: hyl_xx@126.com. operation and the characteristics of parking activities. This will aid in improving parking design and operation strategies. Evaluating parking performance is an important part of the study.

The level of service concept has been widely used in traffic flow evaluations and roadway safety assessments [1], but it has not been widely used in parking facility evaluation mainly due to the lack of a comprehensively developed service model. The quality of parking service from a user's perspective is generally multidimensional, including at least convenience and cost. The commonly used single factor evaluation methods do not sufficiently capture the multifaceted nature of parking performance. Currently, there is no well accepted parking evaluation method available in Beijing. The aim of this paper is to introduce a parking service evaluation method through a comprehensive parking study conducted in Beijing.

\section{Literature Review}

The importance of parking service as a component in any urban transportation system has attracted many studies in the past. In 1973, Yu and Lincoln [2] established a level of service method to measure an 
individual parking facility's efficiency by two factors, parking availability and flow/capacity ratio. Victoria Transport Policy Institute in 2011 [3] defined parking facility level of service by walking distance to destination as a criterion for parking facility's performance evaluation. Another level of service approach was developed by Kay and Smith [4] in 2000, which gave descriptive statement for level of service from the best to the worst mainly based on customers' easiness to find a parking space. Shiftan and Burd-Eden [5] developed a model to evaluate the parking policies. Mildner et al. [6] studied the relationships between level of service of public transit, trips generation and parking behavior. Smith [7] suggested that the level of service of parking facilities should be considered to its entrance/exit, radius curve, grade and so on.

Few parking studies were also conducted in China. Dong and Wang [8] discussed parking facility performance evaluation method based on fuzz mode from three parking aspects: safety, convenience and efficiency, without any actual parking data analysis. Their proposed methodology is mainly based on experts' objective evaluation. Another study conducted by Yang and $\mathrm{He}$ [9] did use parking data and customer survey to analyze the parking performance with multivariate logit model but the modeling results yield a large gap from the real world situation.

In summary, existing parking studies concerning the performance evaluation are either single factor or not quantitative in nature. There has no comprehensive parking performance evaluation method established in China based on customers preferences in multidimensional scale. Lacking a quantitative evaluation method affects quality of parking facility planning, design and operation.

\section{Survey}

A survey was conducted as a part of the Beijing Parking Study project, which consists of two parts with Part One focused on facility type and design characteristics, and Part Two on patrons' parking service evaluation as summarized in Tables 1 and 2. The purpose of Part One survey is to explore the relationship between parking facility design and users' parking behavior and Part Two is to estimate parking patrons' evaluation on the service performance.

The survey results are used in the development of level of service.

\section{Methodology}

\subsection{Selecting Evaluation Variable}

There are quite a few factors affecting parking service, such as type of parking facility, capacity, parking time, ratio of parking space utilization, turnover rate, service charge, walking distance to the destination, etc.. Ratio of space utilization includes both peak-hour and average parking space occupying.

The quality of parking service, to a large extent, depends on vehicle parking characteristics that vary in time and space. It is necessary to select a single parking evaluation index that reflects dynamic parking service. Since the type of a parking facility and its capacity are fixed, they should not be considered in the service assessment. From supply-demand point of view, capacity (the maximum number of parking vehicles can be accommodated at one time) and demand (number

Table 1 Summary of surveyed packing facilities.

\begin{tabular}{lccc}
\hline Parking type & Number of parking facilities surveyed & Existing number of parking facilities & Sampling rate \\
\hline Entity associated parking facility & 167 & 567 & $29.45 \%$ \\
Public & 149 & 1,040 & $14.33 \%$ \\
Yard parking & 39 & 152 & $25.66 \%$ \\
Roadside & 93 & 330 & $28.18 \%$ \\
Residential area & 157 & 1,921 & $8.17 \%$ \\
\hline Total & 605 & 4,010 & $15.09 \%$ \\
\hline
\end{tabular}


Table 2 Summary of parking patron survey.

\begin{tabular}{lc}
\hline Type of parking & Number of samples \\
\hline Public & 858 \\
Office building & 511 \\
Commercial area & 976 \\
School & 0 \\
Cultural and sport event & 30 \\
Industrial & 0 \\
Public transit exchange terminal & 134 \\
Entertainment & 223 \\
Hospital & 324 \\
Residential & 62 \\
\hline Total & 3,118 \\
\hline
\end{tabular}

of parking vehicles at one time) are key factors of service performance. The utilization rate of a single parking space reflects parking time and turnover rate.

Based on the survey, it is also clear that parking charge and walking distance are important for users, which are accounted as the parking access cost. In summary, four variables are selected for parking performance evaluation, which are defined in the following:

(1) Ratio of demand to capacity during peak-hour $\lambda$ :

$$
\lambda=\frac{S_{j}}{C}
$$

where:

$S_{j}$ : number of parking vehicles during peak-hour;

$C$ : parking facility's capacity;

(2) Average parking space utilization rate $\gamma$ :

$$
\gamma=\frac{\sum_{i=1}^{S}\left(t_{i} \cdot P_{i}\right)}{T \times C} \times 100 \%
$$

where:

$t_{i}$ : vehicle parking time in minute;

$P_{i}$ : number of vehicles with parking time $t_{i}$;

$T$ : duration of survey time;

(3) Parking access cost. The parking access cost is defined as multiplication of parking rate and round-trip time (between the parking lot and intended destination);

(4) Parking circulation time. The time spent inside a parking facility looking for available parking space is called parking circulation time, which is related to the parking facility layout, parking management and the ratio of capacity to demand.

\subsection{Variable Classification}

To develop a single index to define the level of service, each selected individual variable is classified first based on the following steps:

- The first step of the procedure is to examining the variable distribution trend. Fig. 1 illustrates the distribution of average space utilization rate, which shows four possible classification groups for level of service. All four variables show similar patterns as in Fig. 1;

- The second step is to define the boundary condition for each potential level of service by applying the $K$-means clustering method with the data showing in Fig. 1 for average parking space utilization rate. $K$-means clustering is a method of cluster analysis which aims to partition $n$ observations into $k$ clusters in which each observation belongs to the cluster with the nearest mean. The results of the clustering analysis for all four variables are given in Table 3 .

After setting up the cluster (level of service), it is important to test whether or not each class is independent. K-S (Kolmogorov-Smirnov) analysis was performed for that purpose. The K-S test results are shown in Table 4.

With the proved independence with the variables' clustering analysis, level of service classification for the four individual variables is defined in Table 5 .

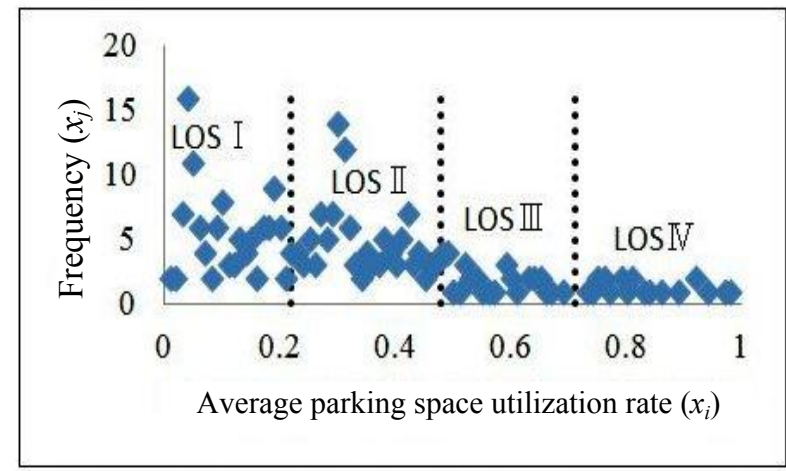

Fig. 1 Distribution of average parking space utilization rate. 
Table 3 Results of clustering analysis.

\begin{tabular}{lll}
\hline Variable name & Class center & Boundary \\
\hline Average parking space utilization $\left(X_{1}\right)$ & $0.10,0.34,0.61,0.80$ & $0.22,0.48,0.71$ \\
Ratio of demand to capacity at peak hour $\left(X_{2}\right)$ & $0.18,0.58,0.85,1.08$ & $0.38,0.72,0.97$ \\
Parking cost $\left(X_{3}\right)$ & $1.01,2.2,3.75,5.17$ & $1.6,3,4.5$ \\
Parking circulation time $\left(X_{4}\right)$ & $3.3,9.5,14.7,21.6$ & $6,12,18$ \\
\hline
\end{tabular}

Table 4 Results of boundary analysis.

\begin{tabular}{|c|c|c|c|c|}
\hline Variable name & Classification & Kolmogorov-Smirnov test & Gradual significance (both ends) & Test of difference \\
\hline \multirow{3}{*}{$X_{1}$} & $\mathrm{~T} 1, \mathrm{~T} 2$ & 6.898 & 0.000 & Significant \\
\hline & $\mathrm{T} 2, \mathrm{~T} 3$ & 6.453 & 0.000 & Significant \\
\hline & $\mathrm{T} 3, \mathrm{~T} 4$ & 4.772 & 0.000 & Significant \\
\hline \multirow{3}{*}{$X_{2}$} & $\mathrm{~T} 1, \mathrm{~T} 2$ & 6.114 & 0.000 & Significant \\
\hline & $\mathrm{T} 2, \mathrm{~T} 3$ & 7.352 & 0.000 & Significant \\
\hline & $\mathrm{T} 3, \mathrm{~T} 4$ & 4.745 & 0.000 & Significant \\
\hline \multirow{3}{*}{$X_{3}$} & $\mathrm{~T} 1, \mathrm{~T} 2$ & 11.381 & 0.000 & Significant \\
\hline & $\mathrm{T} 2, \mathrm{~T} 3$ & 8.367 & 0.000 & Significant \\
\hline & $\mathrm{T} 3, \mathrm{~T} 4$ & 5.430 & 0.000 & Significant \\
\hline \multirow{3}{*}{$X_{4}$} & $\mathrm{~T} 1, \mathrm{~T} 2$ & 11.381 & 0.000 & Significant \\
\hline & $\mathrm{T} 2, \mathrm{~T} 3$ & 8.367 & 0.000 & Significant \\
\hline & T3, T4 & 5.430 & 0.000 & Significant \\
\hline
\end{tabular}

Table 5 Summary of individual variable classification.

\begin{tabular}{llllll}
\hline Variable & \multicolumn{5}{c}{ Classification } \\
\cline { 2 - 5 } & Excellent & Good & Fair & Poor & Unit \\
\hline$X_{1}$ & $<0.22$ & $0.22 \sim 0.48$ & $0.48 \sim 0.71$ & $>0.71$ & None \\
$X_{2}$ & $<0.38$ & $0.38 \sim 0.72$ & $0.72 \sim 0.97$ & $>0.97$ & None \\
$X_{3}$ & $<1.6$ & $1.6 \sim 3$ & $3 \sim 4.5$ & $>4.5$ & Yuan \\
$X_{4}$ & $<6$ & $6 \sim 12$ & $12 \sim 18$ & $>18$ & Minute \\
\hline
\end{tabular}

Table 6 Maximum and minimum of each variable.

\begin{tabular}{lllll}
\hline Variable & $X_{1}$ & $X_{2}$ & $X_{3}$ & $X_{4}$ \\
\hline Maximum $(M j)$ & 1 & 2 & 10 & 60 \\
Minimum $(m j)$ & 0 & 0 & 0 & 0 \\
\hline
\end{tabular}

Table 7 Rsults of zero demension process.

\begin{tabular}{llllll}
\hline Variable & $m_{j}$ & $x_{i}^{a}$ & $x_{i}^{b}$ & $x_{i}^{c}$ & $M_{j}$ \\
\hline$X_{1}$ & 0 & 0.22 & 0.48 & 0.71 & 1 \\
$X_{2}$ & 0 & 0.19 & 0.36 & 0.485 & 1 \\
$X_{3}$ & 0 & 0.16 & 0.3 & 0.45 & 1 \\
$X_{4}$ & 0 & 0.1 & 0.2 & 0.3 & 1 \\
\hline
\end{tabular}

\subsection{Variable Zero Dimension Process}

Since different units for four selected variables are used, it is necessary to make all variables dimensionless before combining them into a single index. To confine values within 0 and 1 , the extreme method is used to make all variables dimensionless by the following equation:

$$
x_{i j}^{*}=\frac{x_{i j}-m_{j}}{M_{j}-m_{j}}, x_{i j}^{*} \in[0,1]
$$

where:

$$
\begin{aligned}
& M_{j}=\text { maximum value of variable } j ; \\
& m_{j}=\text { minimum value of variable } j .
\end{aligned}
$$

The maximum and minimum for each variable are listed in Table 6 and the converted boundaries after dimensionless process are listed in Table 7.

\subsection{Development of Single Evaluating Index}

Having the four individual service variables dimensionless, a parking facility with all variables 
close to 1 is in a positive coordinated state. The parking facility is in a coordinated but poor performance state when all variables are close to 0 . The uncoordinated operating state occurs when a parking facility operates with the individual service performance variables spread to both ends of the spectrum (close to 1 and 0 ). The mixed performance values put the parking facility in an uncoordinated poor performance state, which presents a challenge to evaluate the performance of a parking facility.

A single comprehensive evaluation index is developed by this study that contains all four variables. The principle of this method is graphically explained in Fig. 2 with two variables. In this two-dimensional chart, four levels of service are defined by the three one-fourth of circles.

With the concept illustrated in Fig. 2, the four-dimensional boundary condition, $x_{a}=\left(x_{1 a}, x_{2 a}, x_{3 a}\right.$, $x_{4 a}$ ), for four levels of service can be defined by the following quartic equations:

$$
\begin{aligned}
& \sum_{i=1}^{4}\left(x_{i}^{a}\right)^{2}=\left(r^{a}\right)^{2} \\
& \sum_{i=1}^{4}\left(x_{i}^{b}\right)^{2}=\left(r^{b}\right)^{2} \\
& \sum_{i=1}^{4}\left(x_{i}^{c}\right)^{2}=\left(r^{c}\right)^{2}
\end{aligned}
$$

Thus, with any given dimensionless evaluation set, $x$ $=\left(x_{1}, x_{2}, x_{3}, x_{4}\right)$, the single evaluation index can be calculated as:

$$
y=\sum_{i=1}^{4} x_{i}^{2}
$$

Therefore, the level of service is defined by a single value of $y$ with the threshold condition defined in Tables 8 and 9 .

\section{Case Study}

To demonstrate the application of level of service evaluation method developed in this paper, two case studies are presented in this section.

\subsection{Commercial Parking}

The Blue Harbor parking facility, which is 40,000 $\mathrm{m}^{2}$, is a commercial parking facility located in the Chao-Yang District of Beijing. There are 1,084 parking spaces with 324 parking stalls above the ground and 760 underground. The parking peak-hour occurs between 7:00 p.m. to 10:00 p.m. during weekdays. The ratio of demand to capacity during peak-hour, and average space occupying rate were calculated based on the data from the facility's database. The average parking time and cost were computed based on the survey data. The summary of calculation is given in Table 10 .

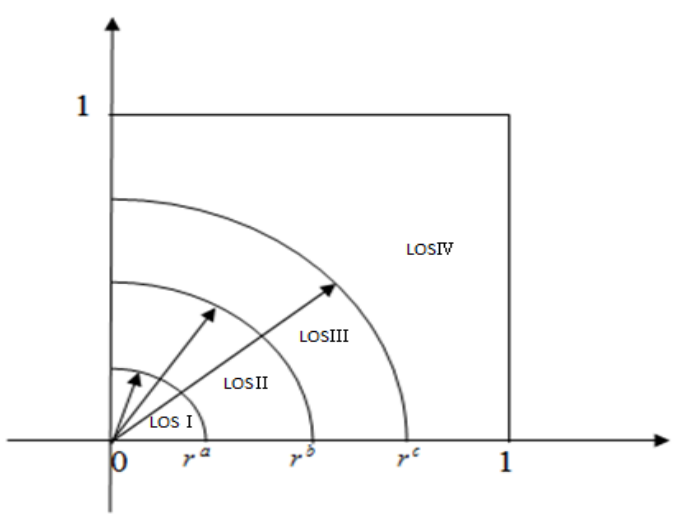

Fig. 2 Illustration of level of service by a single index.

Table 8 Level of service definition.

\begin{tabular}{ll}
\hline $\begin{array}{l}\text { Combined boundary conditions for } \\
\text { variable } y\end{array}$ & Level of service \\
\hline$\leq\left(r^{a}\right)^{2}$ & Excellent-LOS I \\
$\left(r^{b}\right)^{2} \sim\left(r^{c}\right)^{2}$ & Good-LOS II \\
$\left(r^{a}\right)^{2} \sim\left(r^{b}\right)^{2}$ & Fair-LOS III \\
$>\left(r^{c}\right)^{2}$ & Poor-LOS IV \\
\hline
\end{tabular}

Table 9 Value of the boundary.

\begin{tabular}{llll}
\hline & $\left(r^{a}\right)^{2}$ & $\left(r^{b}\right)^{2}$ & $\left(r^{c}\right)^{2}$ \\
\hline Boundary & 0.12 & 0.49 & 1.03 \\
\hline
\end{tabular}

Table 10 Value of the boundary for blue harbor facility.

\begin{tabular}{lllll}
\hline Statistics & Ratio $D$ to $S$ (demand to & Space unitization & Parking cost & Circulation time \\
& capacity) $X_{1}$ & $X_{2}$ & $X_{3}$ & $X_{4}$ \\
\hline Average & 1.086 & 0.53 & 1.4 & 8 \\
Average in dimensionless & 0.543 & 0.53 & 0.14 & 0.13 \\
\hline
\end{tabular}


Table 11 Value of the boundary for Shi-Jing-Shan Hospital facility.

\begin{tabular}{lllll}
\hline Statistics & Ratio $D$ to $S$ & Space unitization & Parking cost & Circulation time \\
& $X_{1}$ & $X_{2}$ & $X_{3}$ & $X_{4}$ \\
\hline Average & 0.912 & 0.814 & 1.3 & 6 \\
Average in dimensionless & 0.465 & 0.814 & 0.13 & 0.1 \\
\hline
\end{tabular}

The level of service index is computed as:

$$
\begin{gathered}
y=\sum_{i=1}^{4} x_{i}^{2}=0.612 \\
\left(r^{b}\right)^{2}=0.51 \\
\left(r^{c}\right)^{2}=1.03 \\
\left(r^{b}\right)^{2}<y<\left(r^{c}\right)^{2}
\end{gathered}
$$

By the definition outlined in Table 9, the level of service for Blue Harbor parking facility is fairly based on the calculated service index above. Located in the center of the city, this parking facility attracts lots of customers throughout the day with 53\% weekly average space utilization rate, which is higher than the majority of other commercial parking facilities in China. Its ratio of peak-hour parking demand to capacity is less than one during weekday and about one at weekend. Most of commercial parking facilities in China are currently located above ground, which severely complicates surface traffic flow (vehicle and pedestrian) during weekend and holidays. It is clear that above ground parking facilities cannot satisfy demand particularly during holidays and weekend when both pedestrian and vehicular flows reach the highest level. Considering that street parking greatly affects traffic flow (both vehicular flow and pedestrian flow), it is important to control surface parking activities and to promote future underground parking development in commercial areas.

\subsection{Shi-Jing-Shan Hospital Parking Facility}

Beijing Shi-Jing-Shan Hospital parking lot belongs to the hospital with 184 surface parking spaces in a $100,000 \mathrm{~m}^{2}$ area. With only one entrance and one exit, the parking lots is very busy during its weekday 8:00 a.m. to 6:00 p.m. peak-hour time period.

The ratio of demand to supply during peak-hour, and average space occupying rate were calculated based on the data from the facility's database. Average parking time and cost were computed based on the survey data. The summary of calculation is given in Table 11.

Thus, the level of service index is computed as:

$$
\begin{gathered}
y=\sum_{i=1}^{4} x_{i}^{2}=0.897 \\
\left(r^{b}\right)^{2}=0.49 \\
\left(r^{c}\right)^{2}=1.03 \\
\left(r^{b}\right)^{2}<y<\left(r^{c}\right)^{2}
\end{gathered}
$$

Although the level of service is fair, the computed $y$ is much close to $\left(r^{c}\right)^{2}$ than the Case Study One. The bigger-than-one ratio of demand to capacity during peak-hour indicates many vehicles could not find parking space right away and have to circulate the parking lots several times, which explains the crowded and sometimes chaos situation that surveyors complained. In fact, majority of surveyors consider that there is a capacity problem at this parking facility.

\section{Conclusions}

Using the survey information, this study develops a comprehensive parking facility service evaluation method called level of service that combined four parking service variables, namely peak-hour demand to capacity ratio, average parking space utilization rate, parking cost, and circulation time, into one single index. Four levels of service are defined as excellent, good, fair, and poor based on the value of the index, which quantitatively evaluates parking facility's performance according to users' perception. The two case studies demonstrate the applicability of this method. The developed level of service can be used not only for performance evaluation but also for parking faculty's planning and design. 


\section{Acknowledgments}

This study is sponsored by Beijing Municipal Institute of City Planning and Design. The authors wish to express their gratitude to all graduate students involved in this project at Beijing University of Technology for their hard work.

\section{References}

[1] Allery, B., and Kononov, J. 2003. " Level of Service of Safety.” In Proceedings of Transportation Research 2358 Record, 57-66.

[2] Yu, J. C., and Lincoln, A. R. 1973. "Parking Facility Layout: Level-of-Service Approach." Journal of the Transportation Engineering Division 99 (2): 297-306.

[3] Victoria Transport Policy Institute. 2011. Parking Evaluation-Evaluating Parking Problems, Solutions,
Costs, and Benefits. Report updated October 11, 2011.

[4] Kay, B., and Smith, M. S. 2000. The Level of Service Approach. France: France Publications, Inc.

[5] Shiftan, Y., and Burd-Eden, R. 2000. "Modeling the Response to Parking Policy." Presented at TRB (Transportation Research Board) 2001 Annual Meeting, Washington, D C.

[6] Mildner, G., Strathman, C. S., Bianco, J. G. I., and Martha, J., 1997. "Parking Policies and Commuting Behavior." Transportation Quarterly 51 (1): 111-25.

[7] Smith, M. S. 2005. Shared Parking. 2nd ed.. Washington, D.C.: ULI-the Urban Land Institute and the International Council of Shopping Centers.

[8] Dong, H., and Wang, Q. 2009. "Based on Fuzzy Theory the Car Park Level of Service Evaluation." Traffic Technology and Economy 6: 14-7.

[9] Yang, H., Hao, S., and Lei, W. 2010. "Research on the Improvement of Urban Public Car Park Level of Service." Transport Standardization May: 87-90. 